\title{
Genome and Transcriptome sequence of Finger millet (Eleusine coracana (L.) Gaertn.) provides insights into drought tolerance and nutraceutical properties
}

Shailaja Hittalmani ${ }^{1{ }^{*}}$, H. B. Mahesh ${ }^{1 * \dagger}$, Meghana Deepak Shirke ${ }^{2}$, Hanamareddy Biradar ${ }^{1}$, Govindareddy Uday ${ }^{1}$, Y. R. Aruna' ${ }^{1}$ H. C. Lohithaswa ${ }^{3}$ and A. Mohanrao'

\begin{abstract}
Background: Finger millet (Eleusine coracana (L.) Gaertn.) is an important staple food crop widely grown in Africa and South Asia. Among the millets, finger millet has high amount of calcium, methionine, tryptophan, fiber, and sulphur containing amino acids. In addition, it has C4 photosynthetic carbon assimilation mechanism, which helps to utilize water and nitrogen efficiently under hot and arid conditions without severely affecting yield. Therefore, development and utilization of genomic resources for genetic improvement of this crop is immensely useful.

Results: Experimental results from whole genome sequencing and assembling process of ML-365 finger millet cultivar yielded $1196 \mathrm{Mb}$ covering approximately 82\% of total estimated genome size. Genome analysis showed the presence of 85,243 genes and one half of the genome is repetitive in nature. The finger millet genome was found to have higher colinearity with foxtail millet and rice as compared to other Poaceae species. Mining of simple sequence repeats (SSRs) yielded abundance of SSRs within the finger millet genome. Functional annotation and mining of transcription factors revealed finger millet genome harbors large number of drought tolerance related genes. Transcriptome analysis of low moisture stress and non-stress samples revealed the identification of several drought-induced candidate genes, which could be used in drought tolerance breeding.

Conclusions: This genome sequencing effort will strengthen plant breeders for allele discovery, genetic mapping, and identification of candidate genes for agronomically important traits. Availability of genomic resources of finger millet will enhance the novel breeding possibilities to address potential challenges of finger millet improvement.
\end{abstract}

Keywords: Next-generation sequencing, Whole genome assembly, Functional annotation, RNA-sequencing, microsatellites, C4 pathway

\section{Background}

Finger millet (Eleusine coracana (L.) Gaertn.) is an allotetraploid $(2 \mathrm{n}=4 \mathrm{x}=36$, $\mathrm{AABB})$ annual cereal millet crop that includes two distinct subspecies: subsp. coracana (cultivated finger millet or ragi) and subsp. africana (wild finger millet) $[1,2]$. Based on morphological, cytogenetic, and molecular evidences, it is believed that

\footnotetext{
* Correspondence: shailajah_maslab@rediffmail.com; maheshhbg@gmail.com ${ }^{\dagger}$ Equal contributors

${ }^{1}$ Marker Assisted Selection Laboratory, Department of Genetics and Plant Breeding, University of Agricultural Sciences, Bengaluru 560065, India

Full list of author information is available at the end of the article
}

modern finger millet (E. coracana subsp. coracana) is domesticated from wild finger millet (E. coracaca subsp. africana) populations [2-5]. The E. coracana subsp. coracana was domesticated around 5000 years ago in western Uganda and the Ethiopian highlands. Subsequently, finger millet was introduced into Western Ghats of India around 3000 BC. Thus India became the secondary centre of diversity for finger millet. It is the fourth most important millet after sorghum, pearl millet and foxtail millet [6]. It occupies $12 \%$ of global millet's area and is cultivated in more than 25 countries in 
African and Asian continents [7]. Finger millet is potentially a climate-resilient and nutritious crop with high nutraceutical and antioxidant properties [8]. Very importantly, finger millet grain is gluten-free, rich in calcium, fiber and iron, has excellent malting qualities, with low glycemic index (GI) and because of these properties, finger millet is a choice food for diabetics [9-11]. In sub-Saharan Africa and South Asia, millets are the survival food crops for resource-poor people. It produces reasonable grain and fodder yields under low input crop production systems and even survives on soils of low fertility. Finger millet grain is used to prepare diverse food cuisines and is highly nutritious. Apart from having rich nutritional value, it has an efficient carbon concentrating mechanism through $\mathrm{C} 4$ pathway. Genes involved in C4 mechanism could be one of the reasons for its hardy nature under low moisture and hot environmental conditions. It is worth comparing genes involved in $\mathrm{C} 4$ carbon assimilation network with already characterized genes from other cereal crops [12-14] and understand the variation at genomic level. In spite of its immense importance in human diet, development of genomic resources and high throughput breeding efforts have been limited. Considering these, we developed the whole genome sequence data for the short duration (110115 days), high yielding (5.0-5.5 tonnes per hectare), drought tolerant finger millet variety ML-365, which was bred and released in 2008 [15]. The present study describes the first de novo genome assembly of orphan nutri-cereal finger millet using combination of Illumina and SOLiD sequencing technologies. The whole genome assembly, SSRs, C4 pathway genes, resistance genes, drought responsive genes and calcium transport and regulation genes will be invaluable genomic resources for the future finger millet studies.

\section{Methods}

Genome size estimation of finger millet and wild species

The ML-365 finger millet variety was developed through recombination breeding by crossing IE1012 and Indaf- 5 in our laboratory earlier. Seeds of ML-365 (Eleusine coracana (L.) Gaertn. subsp. coracana), EC516253 (Eleusine jaegeri Pilg.), EC516251 (Eleusine multiflora Hochst. Ex A. Rich.), EC516248 (Eleusine tristachya Lam.), EC516245, EC516243 (Eleusine indica (L.) Gaertn.), EC541533, and EC541538 (Eleusine coracana subsp. africana) were grown in pots containing red soil and fertilizer mix. Young leaves were collected and chopped into pieces using sterilized blade and stained using nuclear isolation buffer (NIB). The NIB composed of hypotonic Propidium Iodide (PI), $50 \mu \mathrm{g} / \mathrm{ml}$ in $3 \mathrm{~g} / \mathrm{L}$ trisodium citrate dihydride containing $0.05 \%(\mathrm{v} / \mathrm{v})$ of Nonidet P-40 containing $2 \mathrm{mg} / \mathrm{mL}$ RNaseA stored in a dark amber bottle in a refrigerator. The liquid was filtered through $30 \mu \mathrm{m}$ nylon mesh and samples were processed for ploidy estimation as per the protocol suggested by Krishan [16]. Stained nuclei were analyzed using BD FACS cell sorter at Central Imaging and Flow Cytometry Facility (CIFF), Centre for Cellular and Molecular Platforms (C-CAMP), NCBS, Bengaluru, India. Genome sizes of all Eleusine species were estimated by comparing with Pisum sativum as an internal standard since, its nuclear genome is more stable [17, 18 ] and ease in preparation of high quality nuclei suspension, which appear to be free of compounds interfere with PI staining [19]. The genome size was derived by multiplying the $1 \mathrm{C}$ value $(\mathrm{pg})$ with $965 \mathrm{Mb}(1 \mathrm{pg}$ equivalent value) [20].

\section{Nucleic acid isolation}

Genomic DNA (gDNA) was isolated from all cultivated and wild species as per the manufacturer's instruction (Cat \# 69104, DNAeasy Plant Mini Kit) and DNA quality was checked by Nanodrop. The ML-365 finger millet variety was grown in well-watered (WW) and low moisture stress (LMS) conditions in pots under green house condition. Moisture stress was induced on the $80^{\text {th }}$ day after sowing for 10 days [21]. Leaf tissue was sampled on $91^{\text {st }}$ day from WW (soil moisture level was 18.43\%) and LMS (soil moisture level was 9.65\%) plants. Total RNA was isolated using TRIzol reagent (Catalog \#15596026, Invitrogen) and genomic DNA contamination was removed by DNase (Catalogue \# AM1906, Ambion) treatment. The RNA Integrity and quantity was checked on Bioanalyzer using Agilent RNA 6000 nano chip.

Paired-end, mate pair library preparation and sequencing Genomic DNA was used to prepare two independent Illumina paired-end (PE) libraries $(2 \times 151$, and $2 \times 150$ nts) by following manufacturer's instruction using NEXTFlex DNA sequencing kit (catalog \# 5140-02, Bioo Scientific). Pired-end libraries were sequenced using Illumina HiSeq4000 and NextSeq500. Also, three Illumina mate-pair (MP) libraries of insert size $2.5 \mathrm{~Kb}$ were prepared using Illumina Nextera Mate Pair sample preparation gel plus protocol (catalog \# FC-132-1001, Illumina). To prepare SOLiD mate pair library, $3 \mu \mathrm{g}$ of gDNA was fragmented on Covaris S220 and fragmented sample was size selected on $1 \%$ Agarose gel at the range of 3-4 Kb. The size distribution was checked on Agilent Bioanalyzer high sensitivity chip. Then SOLiD MP library was prepared as per the SOLiD mate pair library prep protocol and library was sequenced $(2 \times 61 \mathrm{nts})$ on SOLiD 5500 platform. All the sequencing work was carried out at Genotypic Technology Private Limited, Bengaluru, India. 


\section{DNA-seq data pre-processing and de novo genome assembly}

The raw reads of PE and MP libraries were trimmed for adapter sequence contamination and low-quality bases (PHRED score of <Q30) using FASTX-ToolKit (http:// hannonlab.cshl.edu/fastx_toolkit/). The SOAPdenovo2 [22] assembler was used to assemble all the high-quality PE and MP reads. The contigs were further scaffolded using SSPACE [23] and gaps in the scaffolds were closed by GapCloser module in the SOAPdenovo2 [22]. The genome completeness of assembly was checked by CEGMA [24].

\section{Gene prediction and functional annotation}

The assembled scaffolds were used to predict the genes using AUGUSTUS [25] by Zea mays as a reference gene model. In addition, RNA-seq data was incorporated to AUGUSTUS to assist the gene prediction. The gene ontology annotation was carried out by performing a BLAST with the protein sequences of Viridiplantae retrieved from UniProt database. The pathway analysis of genes was carried out by KAAS server [26] using Arabidopsis thaliana (ath), Glycine max (gmx), Oryza sativa japonica (osa), and Vitis vinifera (vvi) as reference organisms. The protein domain structures of all protein coding genes were identified using InterProScan5 software [27].

\section{Gene families, phylogenetic analysis and mining of transcription factors}

The protein sequences of maize (ftp://ftp.ensemblgenomes.org/pub/plants/release-22/fasta/zea_mays/pep/), sorghum (ftp://ftp.ensemblgenomes.org/pub/plants/release-31/fasta/ sorghum_bicolor/pep/), rice (ftp://ftp.plantbiology.msu.edu /pub/data/Eukaryotic_Projects/o_sativa/annotation_dbs/ps eudomolecules/version_7.0/all.dir/), foxtail millet (http:// foxtailmillet.genomics.org.cn/page/species/download.jsp), and Brachypodium (ftp://ftp.ensemblgenomes.org/pub/ plants/release-31/fasta/brachypodium_distachyon/pep/) were downloaded. The paralogs and orthologs among finger millet, rice, sorghum, maize, foxtail millet, and Brachypodium were identified using OrthoMCL [28]. The groups having at least one copy of gene from each genome were considered as core orthologous groups (COGs). Based on orthoMCL clustering, protein sequences of single copy ortholog gene groups from six species were aligned and inferred phylogenetic relationship as described previously [29]. The consensus phylogenetic tree was drawn using FigTree V1.4.2 (http://tree.bio.ed.ac.uk/software/figtree/). Scaffolds of finger millet genome was concatenated and syntenic relationship among Poaceae species was inferred by Symap tool [30]. Protein sequences of plant transcription factors (TFs) were retrieved from plant transcription factor database (http://planttfdb.cbi.pku.edu.cn/index.php) and used as a reference to identify TFs in ML-365 genes by BLASTP (default e-value cutoff $=10^{-10}$, minimum identity $=40 \%$ and minimum query coverage $=50 \%$ ) alignments.

\section{Analysis of calcium transporter, disease resistant and C4 pathway genes}

We retrieved gene sequences from NCBI database involved in calcium transporter process based on functional annotation like $\mathrm{Ca}(2+) / \mathrm{H}(+)$ antiporter (CAX1), two pore channel (TPC1), CaM-stimulated type IIB Ca(2 +) ATPase, Calmodulin dependent protein kinase 1 and 2 (CaMK) based on previous studies [31, 32]. The predicted Finger millet protein sequences were queried against these protein sequences using BLASTP analysis. Also, the genes containing leucine rich repeats (LRR), coiled-coil (CC), protein kinases (PKs) and NB-ARC domains were identified in finger millet predicted gene set based on protein family (Pfam) annotation using InterProScan 5 software [27]. In order to understand the genes involved in $\mathrm{C} 4$ mechanism, previously characterized $\mathrm{C} 4$ pathway genes from different cereals were used as a reference $[12,13]$ to identify $C 4$ genes in finger millet genome. Homologs with highest identity were selected from finger millet sequenced data for each of the seven $\mathrm{C} 4$ pathway genes viz., phosphoenolpyruvate carboxylase (PEPC), PEPC kinase (PPCK), NADP-malate dehydrogenase (NADP-MDH), NADP-malic enzyme (NADP$\mathrm{ME})$, pyruvate orthophosphate dikinase (PPDK), PPDKregulatory protein (PPDK-RP), and carbonic anhydrase (CA). Ortholog genes from finger millet genome were used for multiple sequence alignment (MSA) and phylogenetic analyses with other C4 cereal genes [33].

\section{RNA-seq library preparation and data pre-processing}

Around $200 \mathrm{ng}$ of total RNA from well-watered (WW) and low moisture stress (LMS) samples was taken and independent paired-end (PE) libraries were prepared using SureSelect Strand Specific RNA library Prep ILM kit (Cat\# 5500-0135, Agilent Technologies). The final libraries were quantified using Qubit and quality was validated on Agilent D1000 ScreenTape system. Finally, the adapter containing fragments were quantified using KAPA library quantification kit (Catalog \# KK4824, KAPA Biosystems) and RNA-seq libraries were sequenced $(2 \times 150 \mathrm{nts})$ using Illumina NextSeq500. The raw reads were pre-processed for adapter contamination and low-quality bases (PHRED score < 30) using FASTX-ToolKit (http://hannonlab.cshl.edu/fastx_toolkit/).

\section{Transcriptome assembly, differential gene analysis and functional annotation}

High quality pre-processed reads from WW and LMS samples were assembled independently using Trinity 
[34]. Unigenes were identified by clustering (90\% homology and 95\% query coverage) the putative transcripts (PUTs) of WW and LMS samples using CD-Hit [35-37]. RNA-seq reads were mapped to unigenes set using Bowtie2 [38] and number of reads mapped per unigenes was counted by in-house script. Differential gene expression between WW and LMS samples was analyzed using DESeq [39]. Functional annotation of putative transcripts was performed by comparing Viridiplantae protein sequences in UniProt database (http://www.uniprot.org/taxonomy/33090). Transcripts with more than $30 \%$ protein homology were considered for downstream analysis.

Validation of drought responsive genes through qRT-PCR Equal amount of total RNA of WW and LMS samples was used to synthesize complementary DNA (cDNA) using RevertAid First Strand cDNA synthesis kit (K1622, ThermoFisher Scientific). Twenty micro litres of reaction mixture containing SYBR Premix Ex Taq (RR420A, TaKaRa), ROX reference dye, $10 \mu \mathrm{M}$ of each of forward and reverse primers, and template cDNA was used to perform qRT-PCR in Corbett RotorGene 6000. Two biological replicates and three technical replicates were amplified for all samples. All the ' $\mathrm{Ct}$ ' values were normalized based on ' $\mathrm{C} t$ ' value of elongation factor housekeeping gene and differential gene expression (fold change) was calculated as per $2^{-\Delta \Delta C t}$ method.

\section{Simple and complex repeat prediction}

Transposable elements (TEs) were identified in finger millet genome using a combination of de novo and reference based approaches. Finger millet repeat database was built using RepeatModeler and repeats were predicted using RepeatMasker 4.0.5 (http://www.repeatmasker.org). Similar approach was followed to identify TEs in Trinity assembled transcripts from RNA-seq data. The simple sequence repeats (SSRs) were predicted genome-wide using Microsatellite Identification tool [40] (http://pgrc.ipk-gatersleben.de/misa/misa.html) and categorized as Class I and II based on the previous report [41].

\section{Primer designing for SSRs and electronic PCR}

Primers were designed for flanking sequences of SSRs using Primer3 tool (the criteria set were like $\mathrm{GC}=50$ $55 \%, \mathrm{Tm}=55-65{ }^{\circ} \mathrm{C}$ and product length $=100-350 \mathrm{bp}$ ). Primer sequences overlapping with repetitive elements were eliminated. The efficacy of designed primers was checked by e-PCR [42] (five bases mismatches were allowed at a primer binding site) and primer sequences hitting multiple sites in the genome were eliminated. Randomly, 35 SSRs comprising di-, tri-, tetra-, penta-, and hexa-nucleotide types were selected for wet lab validation.

\section{Oligo synthesis and genotyping of finger millet} accessions

Oligos were synthesized at Eurofins Genomics Private Limited, Bengaluru, India. DNA from young leaf samples was isolated using CTAB method [43]. We set up $10 \mu \mathrm{l}$ volume PCR reaction containing $20 \mathrm{ng}$ of genomic DNA, $5 \mu \mathrm{l}$ of emeraldAMP GT PCR master mix (Cat \# RR310A, Takara), $0.5 \mu \mathrm{l}$ of $10 \mathrm{mM}$ of each forward and reverse primers. PCR amplification was carried out in Eppendorf vapo protect with initial denaturation temperature at $95^{\circ} \mathrm{C}$ for $3 \mathrm{~min}$ followed by 30 cycles with $30 \mathrm{~s}$ at $95^{\circ} \mathrm{C}, 30 \mathrm{~s}$ of annealing temperature $\left(55^{\circ}\right.$ C), $1 \mathrm{~min}$ of $72^{\circ} \mathrm{C}$, final extension for $5 \mathrm{~min}$ at $72^{\circ} \mathrm{C}$. PCR products were resolved on $3.5 \%$ agarose and $8 \%$ PAGE (only for monomorphic primers) stained with Ethidium bromide (final concentration at $0.5 \mu \mathrm{g} / \mathrm{mL}$ ) and visualized using gel documentation unit.

\section{Results and Discussion}

Estimation of genome size of ML-365 finger millet variety and related eleusine species

ML-365 variety was developed in our laboratory as a part of collaborative research funded by the McKnight Foundation, USA (http://www.ccrp.org/sites/default/files/ finger_millet__year_4__development_of_high-yielding_disease-resistant_and_drought-tolerant_finger_millet_genotypes.pdf) through farmer's participatory varietal selection approach and released for commercial cultivation in 2008 in India. It is a drought tolerant, blast disease resistant variety possessing good cooking qualities preferred by farmers and consumers. Over the years, it has spread across several thousands of hectares and survives very well under long spells of drought.

In order to estimate the genome size of cultivated and wild species of Eleusine, the samples were subjected to flow cytometry analysis. One accession each of $E$. jaegeri, E. multiflora, and ML-365, and two accessions of $E$. triastachya, E. indica, E. coracana subsp. africana species were chosen. The average DNA content ( $2 \mathrm{C}$ value) of E. jaegeri, E. multiflora, E. tristachya, E. indica, E. coracana subsp. africana was $1.20 \mathrm{pg}, 1.84 \mathrm{pg}, 1.14 \mathrm{pg}$, $1.21 \mathrm{pg}, 2.52 \mathrm{pg}$, respectively. The genome size of wild species ranged from $580 \mathrm{Mb}$ (E. jaegeri) to $1217 \mathrm{Mb}(E$. coracana subsp. africana). The total DNA content (2C value) and genome size of ML-365 (E. coracana) were $3.01 \mathrm{pg}$ and $1453 \mathrm{Mb}$, respectively (Fig. 1). The genome sizes of E. coracana subsp. coracana and E. coracana subsp. africana are relatively similar. This could be because, finger millet was domesticated from E. coracana subsp. africana [2-5]. Several studies indicated that $E$. indica could be the maternal donor of 'A' genome of $E$. coracana subsp. coracana and ' $\mathrm{B}$ ' genome donor is yet to be deciphered $[44,45]$. Few studies showed that $E$. floccifolia is the ' $\mathrm{B}$ ' genome donor [46-48]. However, waxy 


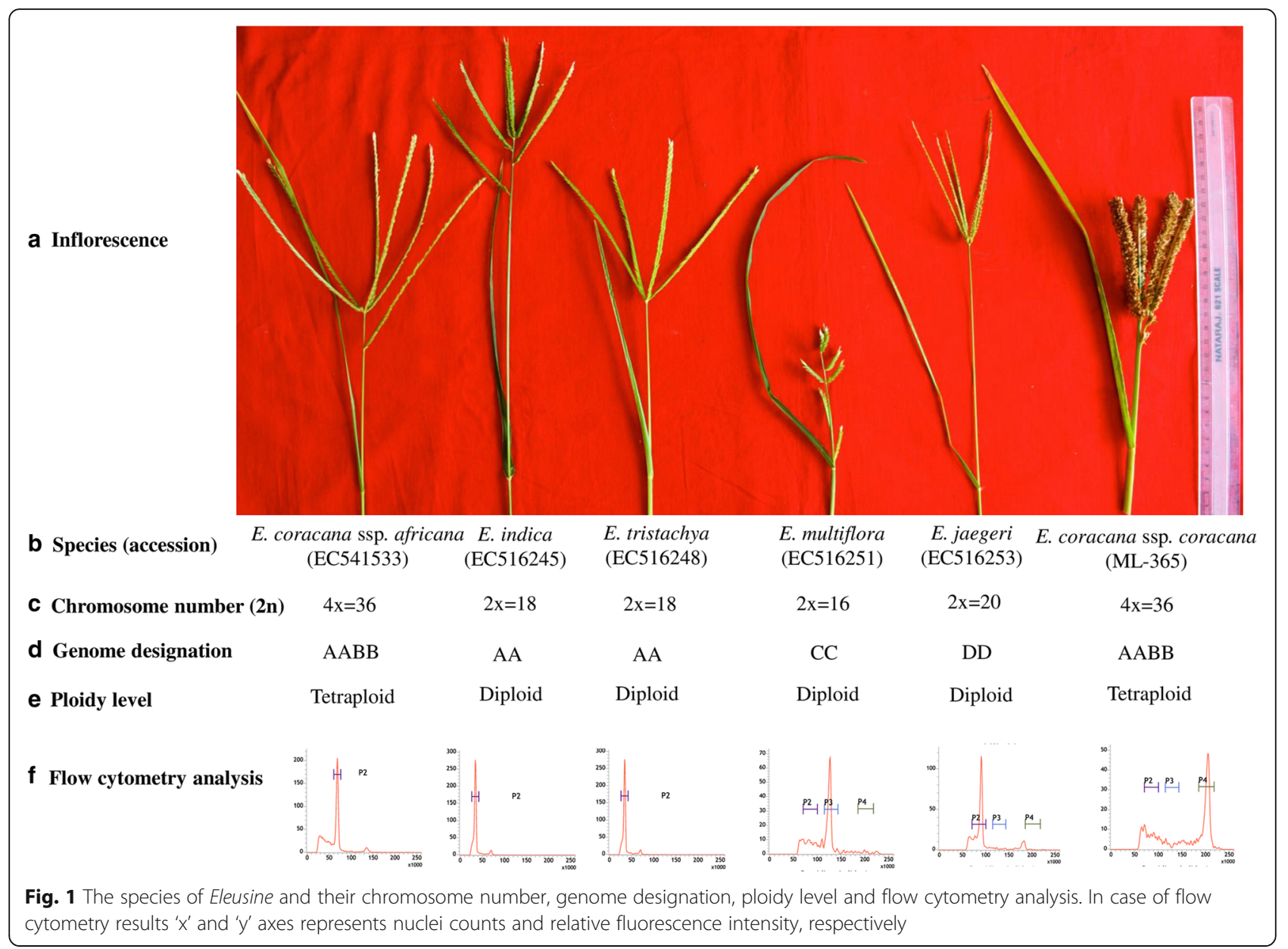

sequence and multicolor genomic in situ hybridization (McGISH) studies revealed that 'B' genome donor must have become extinct or yet to be uncovered [49]. Genome sequencing of wild species of 'A' and 'B' genomes, comparison with tetraploid cultivated species (E. coracana subsp. coracana) resolve the ambiguity of the progenitors.

\section{Genome sequencing and genome assembly}

Around $45 \mathrm{~Gb}$ of paired-end and $21 \mathrm{~Gb}$ of mate-pair data was generated using Illumina and SOLiD sequencing technologies (Additional file 1). Combination of paired-end and mate pair reads were used to assemble the ML-365 genome followed by gap closing yielded $1196 \mathrm{Mb}$ of consensus genome size, representing 82.31\% of the estimated finger millet genome (Additional file 2). The assembly consisted of 525,759 scaffolds ( $>200 \mathrm{bp}$ ) with N50 length of $23.73 \mathrm{~Kb}$ (Table 1) and the average length of scaffolds was $2275 \mathrm{bp}$. Genome assembly was filtered for mitochondrion, chloroplast, fungal, and bacterial sequence contaminations. We further evaluated the ML-365 scaffolds for genome completeness by Core Eukaryotic Gene Mapping Approach (CEGMA) tool. Results showed that around $94.35 \%$ of core eukaryotic genes (CEG) were present in the ML-365 genome (Additional file 3 ). Highly self-pollinated behavior, small flower size, narrow genetic base of germplasm, lack of precise information on trait values of wild species for their inclusion in finger millet improvement, highly neglected in terms of research as compared to crops like

Table 1 Genome assembly statistics of ML-365

\begin{tabular}{ll}
\hline Details & Value \\
\hline Total length of sequence (Mb) & 1196.06 \\
No. contigs/scaffolds & 525,759 \\
Minimum length of contigs/scaffolds (bp) & 200 \\
Maximum length of contigs/scaffolds (bp) & 454,778 \\
Average length of contigs/scaffolds (bp) & 2274.92 \\
N50 (bp) & 23,732 \\
GC content (\%) & 44.76 \\
No. of genes predicted & 85,243 \\
a. Non-TE related genes & 78,647 \\
b. TE related genes & 6596 \\
\hline
\end{tabular}

Mb Million bases

bp base pairs 
rice, wheat and maize at national and international level, are the major factors behind limited breeding improvements of this crop [50-52]. However, hybridization between Indian and African germplasm resulted into development of several 'Indaf' series of finger millet varieties, which have gained popularity in the farmer's field. Later on, the first major milestone in finger millet genomics is the development of first detailed genetic linkage map in $\mathrm{F}_{2}$ population by crossing E. coracana subsp. coracana cv. Okhale-1 and its wild progenitor E. coracana subsp. africana acc. MD-20 [53]. Since then, few researchers have concentrated on assessing the genetic variability among finger millet population and QTL mapping for important traits [4, 54-56]. However, gene cloning, Marker Assisted Selection (MAS), genomewide association studies in finger millet are inadequate. The availability of whole genome assembly of ML-365 will expedite the improvement of finger millet.

\section{Gene prediction and functional annotation of genes}

We predicted, 78,647 non-TE related and 6596 TE related genes summing up to a total of 85,243 genes in ML-365 genome based on de novo method of gene prediction using Augustus. Functional annotation confirmed that majority of the genes had homologs with known functions in UniProt protein database. The gene ontology (GO) annotation of genes revealed that more number of genes were involved in molecular function followed by cellular and biological processes. Majority of the genes were involved in nucleic acid binding, zinc ion binding, and ATP binding activities under molecular function. Similarly, DNA integration and integral components of membrane were major functions related to biological and cellular processes, respectively (Fig. 2a). The KAAS server based pathway prediction showed that majority of genes were involved in carbohydrate metabolism,

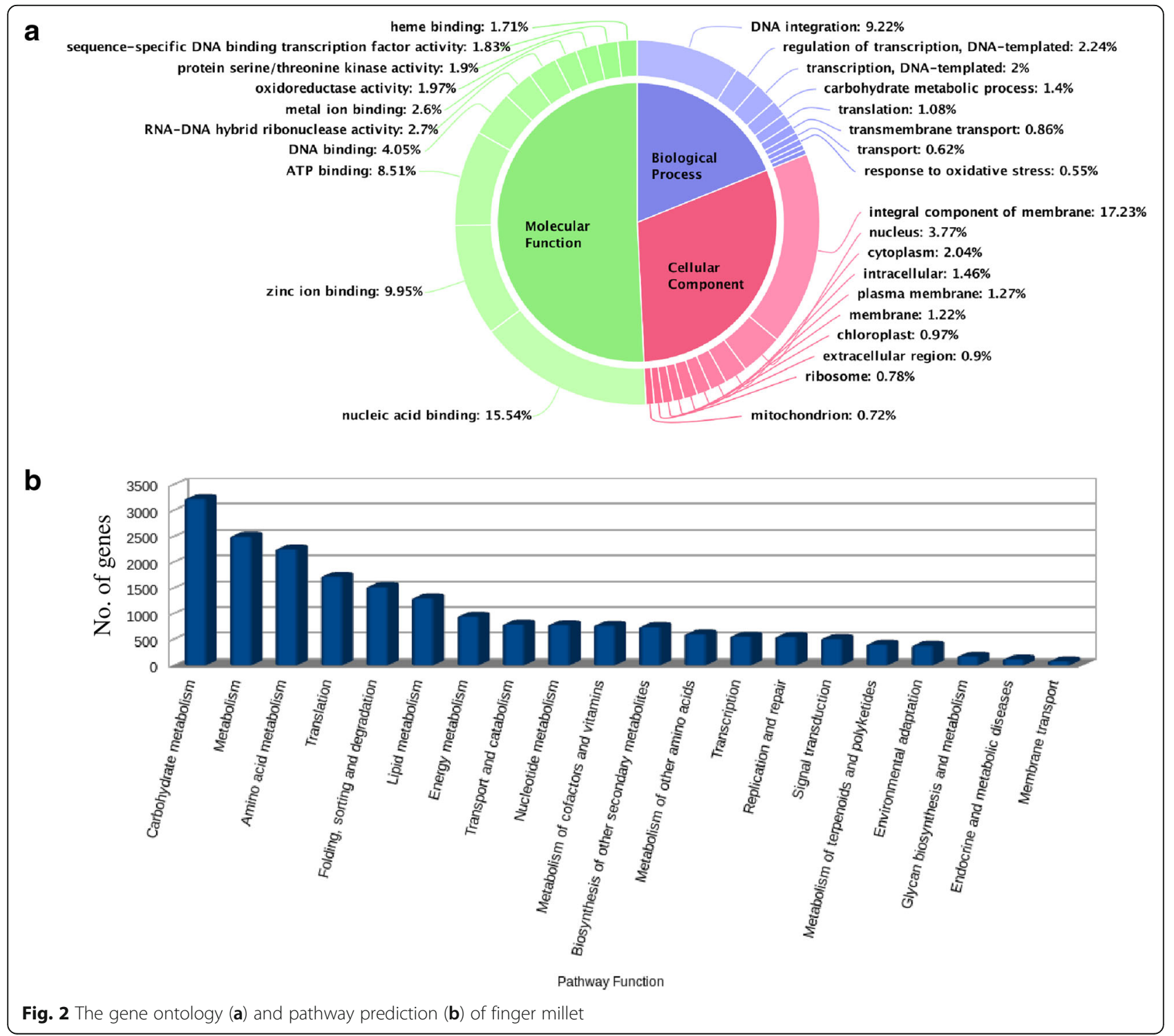


amino acid metabolism, translation, lipid metabolism and folding, sorting, and degradation pathways (Fig. 2b). Out of 85,243, 52,541 genes contained Pfam domain as per InterProScan results and these genes were distributed across 3254 gene families. Among 3254, retrotransposon gag protein, gag-polypeptide of LTR copia-type, reverse transcriptase, zinc knuckle, putative gypsy type transposon, protein kinase, cytochrome P450, and integrase core domain were the major gene families.

\section{Gene family orthologs and synteny with other sequenced Poaceae species}

The ortholog gene families across species provide insight into co-evolution of plant species. Clustering of genes of six Poaceae species (Finger millet, Rice, Foxtail millet, Sorghum, Maize, and Brachypodium) using OrthoMCL tool resulted in 10,291 core orthologous groups (COGs) gene families shared by all six species (Fig. 3). These families could have arisen due to whole genome duplication event. Among COGs gene families, 23,332 (35.22\%) of rice, 24,427 (28.66\%) of finger millet, 17,212 (47.37\%) of sorghum, 27,401 (43.33\%) of maize, 15,927 (41.05\%) of foxtail millet and 17,888 (57.65\%) of Brachypodium genes formed core gene families common to all species. However, within those COGs, 6107 (9.22\%) of rice, 2976
(3.49\%) of finger millet, 7337 (20.19\%) of sorghum, 4403 (6.96\%) of maize, 7879 (20.31\%) of foxtail millet and 6999 (22.56\%) of Brachypodium genes have retained single copy. Remaining genes were in multiple copies and these expansions or contractions of gene families have a significant role in diversification of flowering plants $[57,58]$. The expanded gene families belonged to zinc knuckle, reverse transcriptase, aspartyl protease, leucine rich repeat, gag-polypeptide, gypsy type transposon, integrase, and ATHILA ORF-1 family protein domain containing genes. Single copy orthologous gene (766 genes across six species) based phylogeny among six species revealed that finger millet is closer to rice followed by foxtail millet (Fig. 4).

Intergenome collinear analyses between finger millet, Brachypodium, foxtail millet, sorghum, maize, and rice showed highly conserved genomic regions, signifying close evolutionary relationship among these grass species. In total, we identified 1592 large collinear blocks between finger millet and rice; 1709 between finger millet and foxtail millet; 1693 between finger millet and sorghum; 1613 between finger millet and maize; 436 between finger millet and Brachypodium, indicating 97\%, $98 \%, 95 \%, 96 \%$, and $82 \%$ of finger millet genome is colinear with these grass species, respectively (Fig. 5).

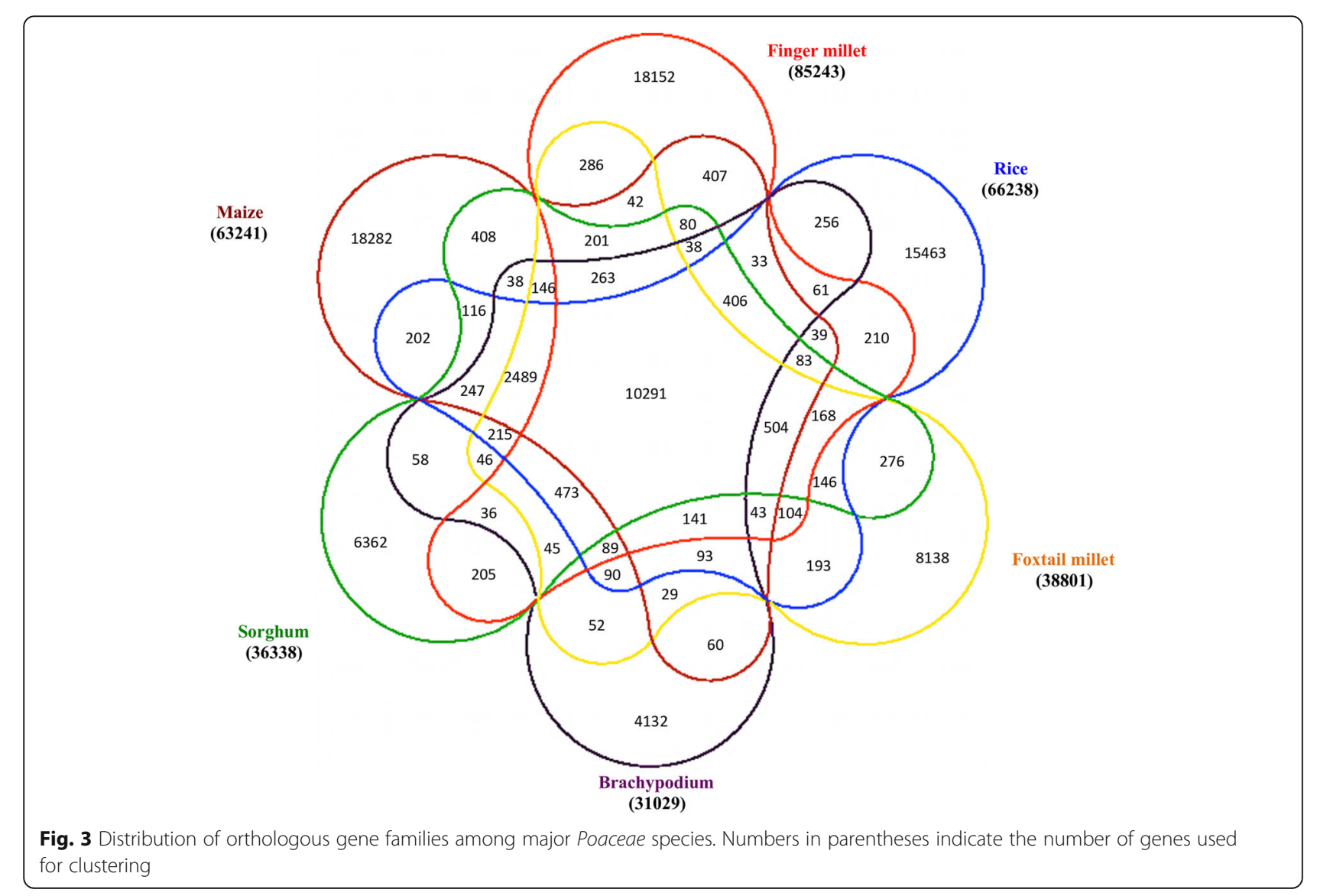




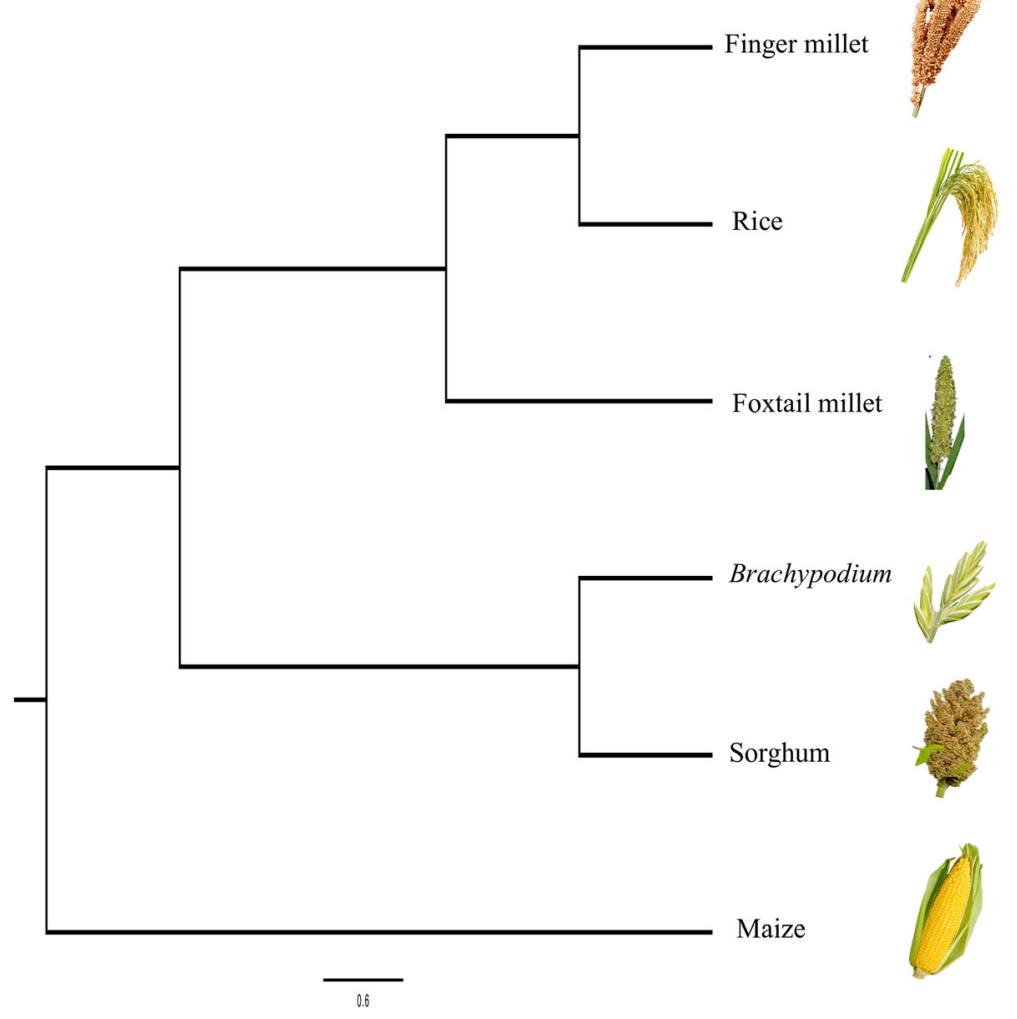

Fig. 4 Phylogenetic relationship of six Poaceae species revealed based on single copy ortholog genes

Previous comparative analysis also revealed more number of conserved genomic regions between finger millet and rice genomes [59]. This syntenic relationship of finger millet with other cereal crops will enable us to map orthologous candidate Quantitative Trait Loci (QTLs) or genes of interest [60-63].

\section{Repeat content in finger millet genome}

Transposable elements are the major components of eukaryotic genomes and their integration in the genome play a vital role in genome evolution and duplication. The assembled scaffolds were analysed for repeat content using RepeatModeller and RepeatMasker tools. We annotated finger millet genome using de novo constructed repeat library indicating around $49.92 \%$ of finger millet genome is repetitive. The retroelements constitutes around $35.56 \%$, LTR elements were the major components (33.26\%) among retroelements. Subsequently, unclassified repeats and DNA transposons were found in minor fractions of $9.73 \%$ and $4.48 \%$, respectively (Table 2). Previous report also indicated the richness of finger millet genome with repeats based on DNA reassociation kinetics [64]. This repetitive nature of the finger millet genome is attributed to larger lengths of interspersed DNA repeats as reported in pearl millet $[64,65]$. We predicted the repeat content in a similar manner like genome in Trinity assembled putative transcripts, the overall repeat content was found to be $4.87 \%$. Most of this fraction (4.28\%) was constituted unclassified repeats and remaining was simple and low complexity repeats.

Simple sequence repeats (SSRs) play an evolutionary relationship in genome evolution. The scaffolds of ML365 genome were subjected for identification of SSRs using MISA. A total of 114,083 SSRs were distributed across ML-365 genome signifying the abundance of SSRs [66], of which 66,805 (58.56\%), 40,578 (35.57\%), 2179 (1.91\%), 3010 (2.64\%) and 1511 (1.32\%) were di-, tri-, tetra-, penta-, and hexa- types, respectively. Among di-repeats, AG/CT (66.64\%) were highest followed by AT/AT (17.21\%), AC/GT (12.96\%) and CG/CG (3.20\%) types. Similarly, AAG/CTT were the highest among trirepeats types followed by CCG/CGG (15.13\%), ATC/ ATG (14\%), AGG/CCT (13.19\%), AAC/GTT (13.30\%), ACC/GGT (7.55\%), AAT/ATT (7.54\%), AGC/CTG (7.47\%), ACG/CGT (2.78\%) and ACT/AGT (1.82\%) (Fig. 6). In case of tetra type repeats, AAAT/ATTT (21.48\%) and AAAG/CTTT (19.55\%) were higher as compared to other types of tetra type repeats. The penta repeats, AAAAG/CTTTT (10.76\%) and AAAAT/ATTTT (10.20\%), and among the hexa repeats, AACACC/ GGTGTT (13.70\%) were found to be in higher proportion. Primers were designed for di-, tri-, tetra-, penta-, 


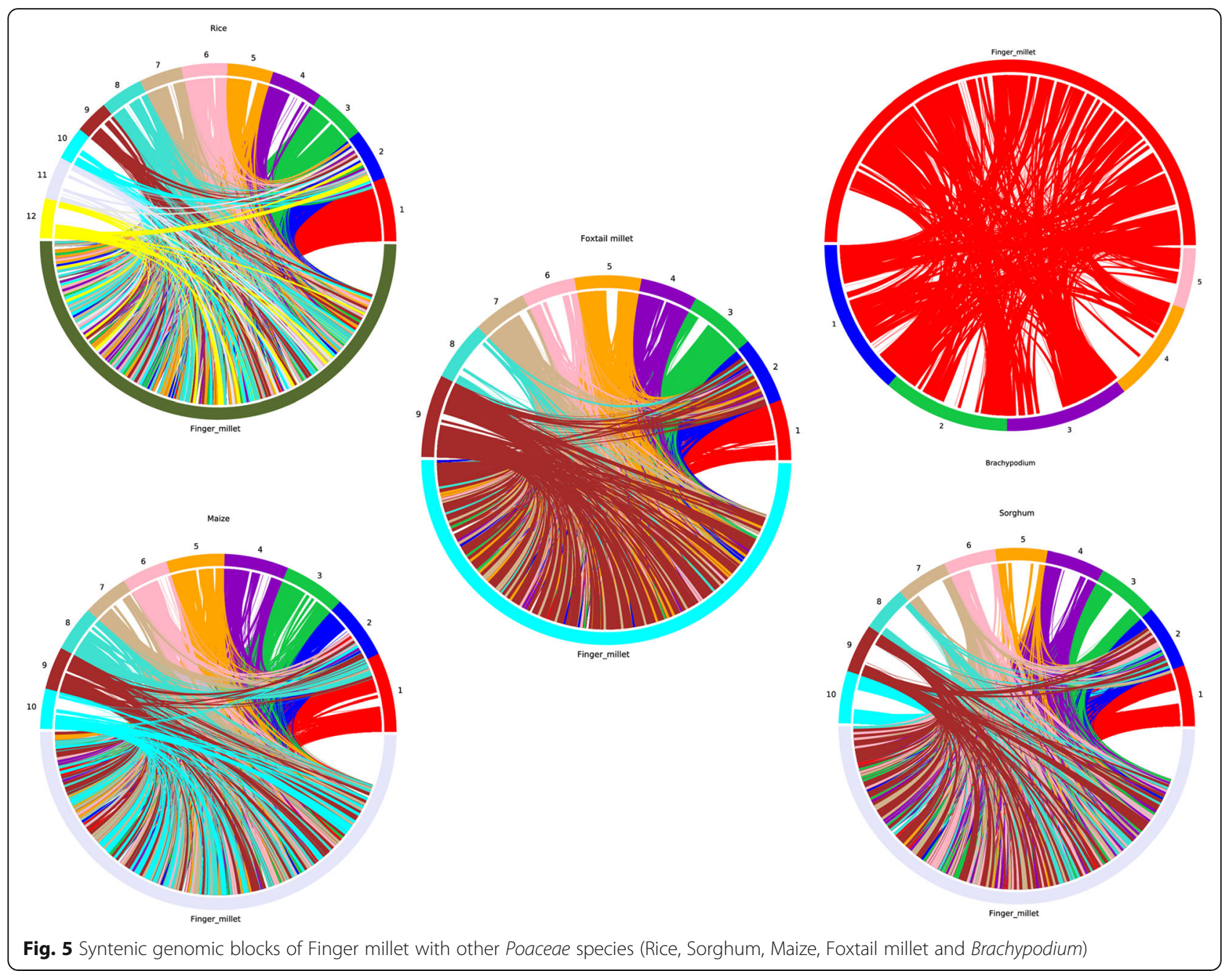

Table 2 Repeat content in ML-365 finger millet genome

\begin{tabular}{lll}
\hline Repeat type & No. of copies & Percent (\%) \\
\hline Total interspersed repeats & & 49.77 \\
A. Retroelements & 754,889 & 35.563 \\
$\quad$ SINEs: & 8647 & 0.127 \\
LINEs: & 69,277 & 2.175 \\
$\quad$ LTR elements: & 676,965 & 33.261 \\
ERV_classl & 1430 & 0.025 \\
$\quad$ ERV_classll & 1318 & 0.044 \\
B. DNA transposons & 196,245 & 4.477 \\
C. Unclassified: & 432,219 & 9.734 \\
Small RNA & 8450 & 0.130 \\
Satellites & 182 & 0.002 \\
Simple repeats & 1404 & 0.012 \\
Total & & 49.92 \\
\hline
\end{tabular}

SINEs Short Interspersed Elements LINEs Long Interspersed Elements LTR Long Terminal Repeat and hexa- types of SSRs using Primer3 software. Primer sequence flanking the repetitive regions and primers generating multiple amplimers were eliminated using ePCR and finally 18,514 SSRs were shortlisted for future applications (Additional file 4). The wet lab PCR validation of randomly chosen 35 SSRs in ML-365 confirmed the in silico e-PCR results (Fig. 6). Also, fingerprinting of 26 finger millet accessions, 14 wild species revealed minor allelic variation on 3.5\% agarose gel for 35 SSRs (Additional file 5). However, when PCR amplified products were resolved on PAGE, the extent of polymorphism observed was much higher. In addition, we observed higher polymorphism in case of wild species of finger millet as compared to Eleusine coracana germplasm on PAGE gels. The inherent drawback of low polymorphism in finger millet was observed in previous studies [67, 68]. However, SSRs identified in this study can be further effectively used in diversity studies, linkage map construction, association mapping, QTL mapping of agronomically important traits, and marker assisted breeding programmes. 


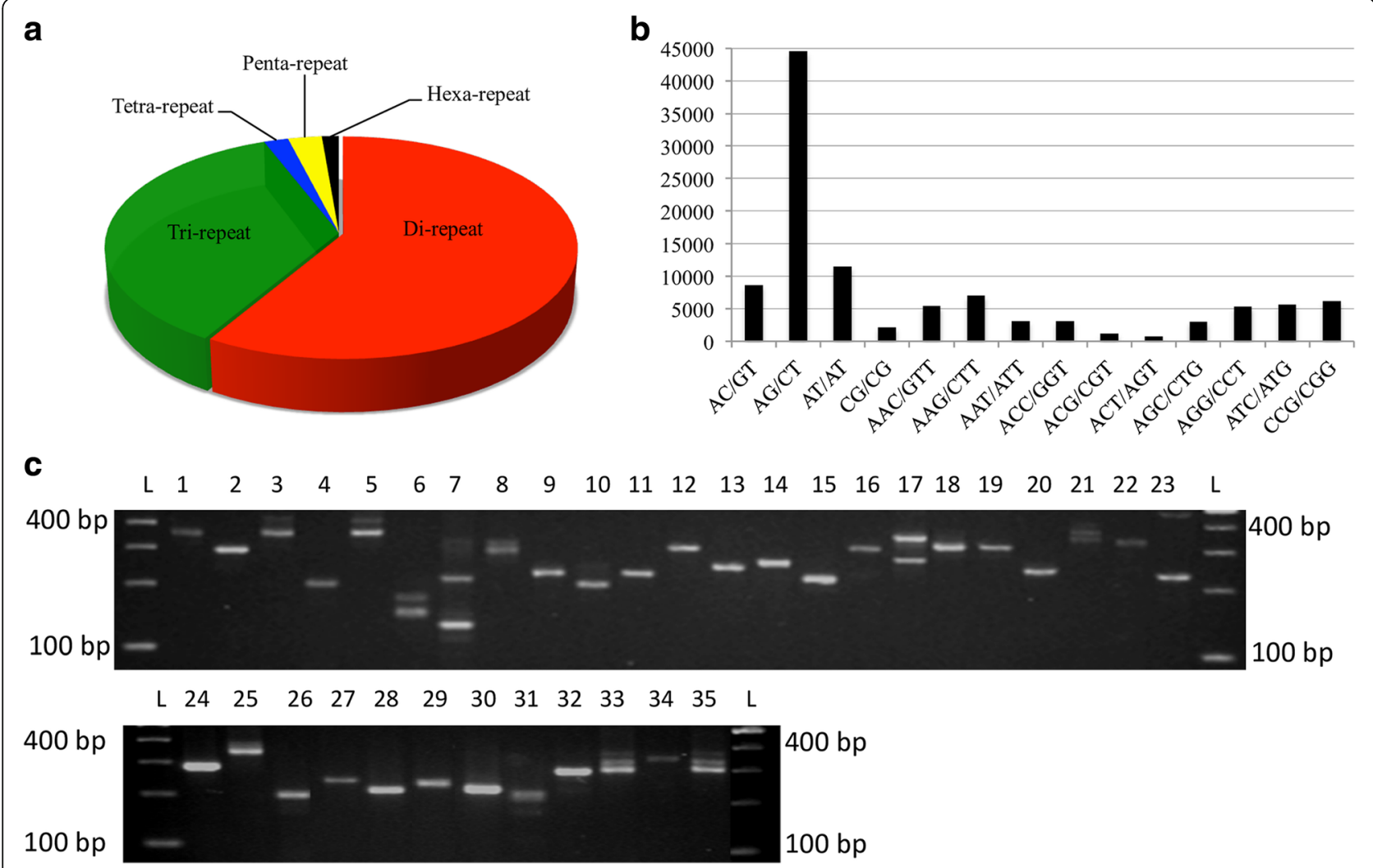

Fig. 6 Distribution of SSRs (a), (b) and allelic variation (c) of selected SSRs in ML-365 finger millet variety

Transcriptome assembly and gene expression study in contrasting moisture regimes

Independent transcriptome assembly was performed for well-watered (WW) and low moisture stress (LMS) samples using Trinity. The number of transcripts assembled in WW and LMS samples were 53,300 and 100,046, respectively. These transcripts were clustered (based on 90\% homology and 95\% query coverage using CD-Hit) to make unique putative transcripts (PUTs)/unigenes and finally 126,312 PUTs were used for differential gene expression. Around 64\% of PUTs were annotated against viridiplantae protein sequences from UniProt database. Large number of transcripts were known to be of ATP binding and zinc ion binding types under molecular function. Similarly, transcripts involved in membrane integral component and transcription regulation activities were more for cellular and biological processes, respectively (Fig. 7).

Differential gene expression between WW and LMS samples showed that 111,096 unigenes were expressed in both the samples. Few unigenes were expressed only in specific conditions like WW (2287 unigenes) and LMS (12,893 unigenes) conditions. Out of 111,096 common genes, 25,796, 23,210 and 62,090 genes were up, down and neutral in regulation, respectively. Around 4859 genes were significantly (' $p$ ' value less than 0.05 ) expressed between WW and LMS conditions. Out of which, 2333 were up-regulated and 2526 were downregulated in LMS as compared to WW condition. The protein domain (Pfam) annotation of these genes showed that only 1099 genes in up-regulated and 1883 genes in down-regulated had Pfam designation. Among up-regulated genes, majority belonged to protein kinase domain (PF00069), Myb-like DNA-binding (PF00249), pectinacetylesterase (PF03283), protein tyrosine kinase (PF07714), zinc-binding (PF13966), Hsp20/alpha crystalline family (PF00011), protein phosphatase 2C (PF00481), and late embryogenesis abundant protein (PF02987). Also, protein kinase, protein tyrosine kinase, cytochrome P450, NB-ARC, UDP-glucoronosyl and UDP-glucosyl transferase Pfam domains were in majority among down-regulated genes. Three up (g161426.t1, g77173.t1 and g86441.t1) and two down (g134601.t1 and g40229.t1) regulated drought responsive genes were validated by qRT-PCR in WW and LMS samples for the proof of concept. The pattern of their regulation was in concordance with the RNA-seq results (Additional file 6). Several drought responsive genes have been characterized in finger millet using various methodologies. However, their deployment in breeding drought tolerant finger millet genotypes have not been attempted [21, 69-71]. Hence, genes identified in this study could make 


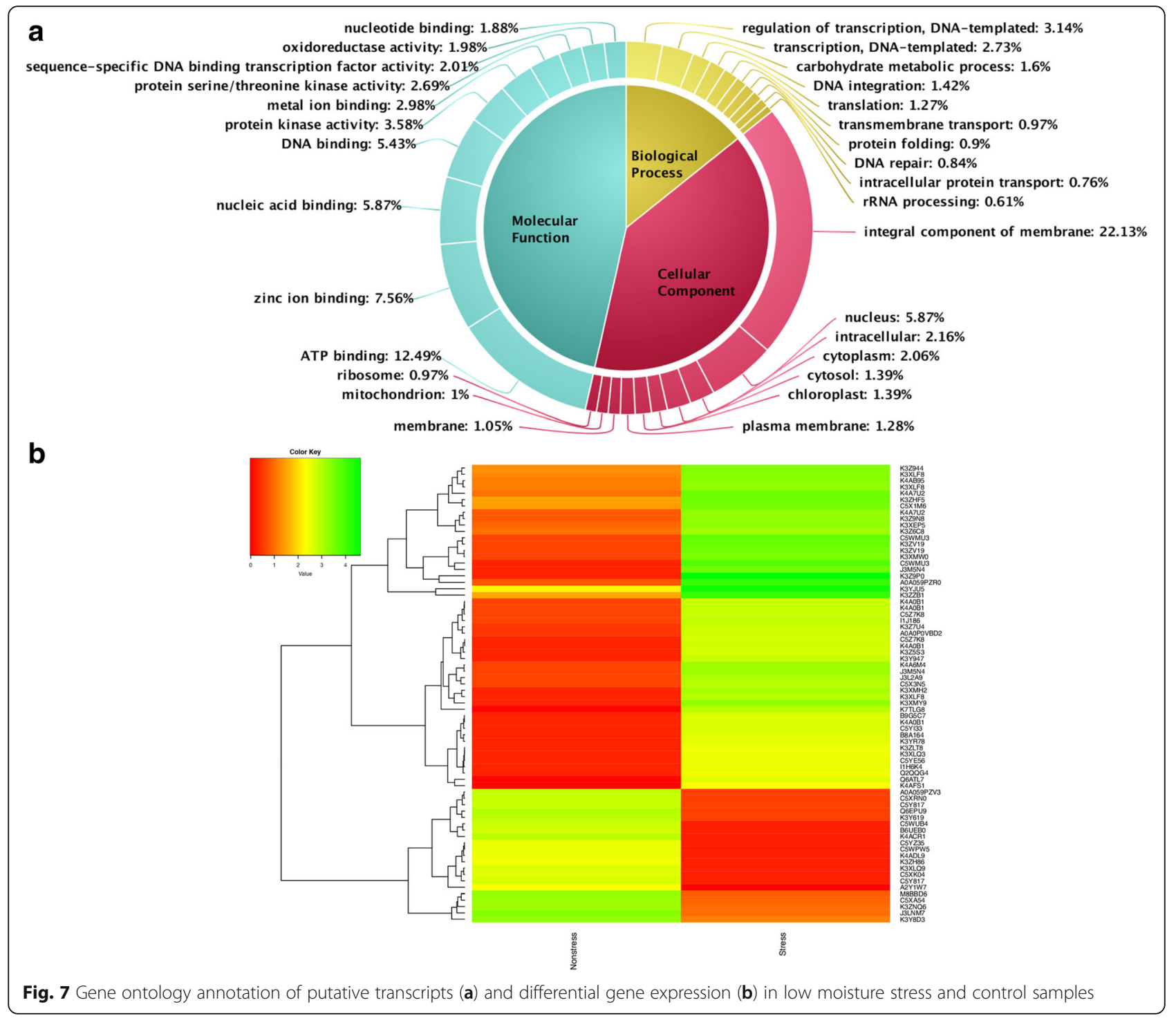

a remarkable impact in drought tolerance breeding. Characterization of these genes further would provide insights on the importance of these genes to utilize them in finger millet or other food crops to impart abiotic stress-tolerance.

\section{Mining of plant transcription factors (TFs) in finger millet}

The protein-protein homology analysis of genes of ML365 with plant TFs protein database revealed 56 various families of TFs distributed across 11,125 genes in finger millet. Among them, bHLH, MYB, FAR1, WRKY, NAC, MYB related, B3, ERF, bZIP, HD-ZIP, C2H2, C3H, G2like, TALE, GRAS, ARF, M-type, Trihelix, GATA, WOX, LBD, HSF, MIKC, S1Fa-like, HB other, CPP, and YABBY were majorly distributed TFs in the finger millet genome (Fig. 8). These 11,125 genes were found to have homology with 75 plant species and foxtail millet, rice, wild species of rice, apple, Brachypodium, maize, sorghum, wheat and wild species of wheat (Additional file 7) were major among other plant species.

\section{Mining of drought responsive and disease resistance genes}

Finger millet is a drought tolerant cereal crop and mining for drought responsive genes will hasten future breeding activities to develop varieties for drought prone areas. The Pfam based identification of drought responsive genes revealed that 2866 genes were distributed across 19 Pfam domains. The protein kinases (PF00069), protein tyrosine kinases (PF07714), BTB/POZ (PF00651), NAD dependent epimerase/dehydratase family (PF01370), U-box (PF04564), universal stress protein family (PF00582), and DCPS (PF00571) domains containing genes were majorly distributed in ML-365 genome (Table 3). Most of these genes were associated with WRKY, MYB, MYC, ZFHD, NAC, ABF, AREB, GRF, and NF-Y 


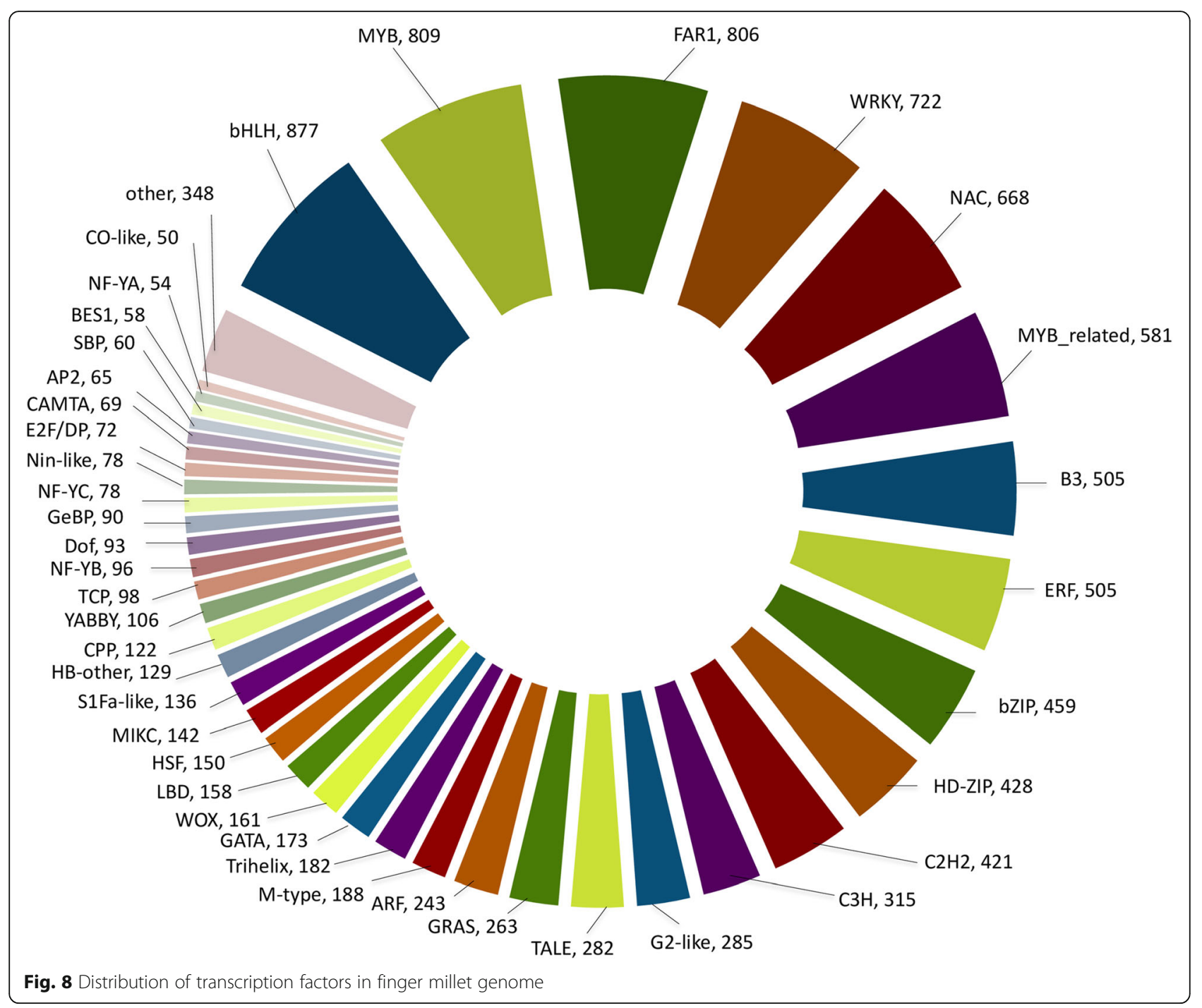

transcription factors, which are responsible for drought tolerance [72-75]. Utilization of these TFs to study the binding sites of TFs and analyzing cis-acting elements will enhance further understanding of drought tolerance in finger millet. Hence, identification and prediction of cisregulatory elements through promoter analysis is a crucial step in functional analysis and signaling networks. Several novel technologies like overexpression, RNAi, zinc finger nucleases (ZFNs), transcription activator-like effector nucleases (TALENs), and clustered regulatory interspaced short palindromic repeats (CRISPRs) technologies to understand the role of these TFs in finger millet will have major impact in breeding for abiotic stress tolerant varieties $[76,77]$.

Finger millet blast caused by an Ascomycetes fungus, Magnaporthe grisea is a devastating disease. Blast pathogen attacks the plant at three different plant growth stages viz., seedling, finger and neck [78]. The estimated yield loss due to blast is around $28 \%$, but under favorable condition it may be up to $80-90 \%$ [79-81]. So far, no resistance genes (R-genes) have been mapped in finger millet except few recent studies [82, 83]. We looked for R-genes in the predicted gene set of ML-365. Totally, 1766 genes were identified with domains of NBARC (250), LRR (471), CC (6) and PKs (1044) (Additional file 8). Seventy-six NB-ARC genes identified in this study have homologs with previously identified genes (ABW04964.1, ABW04969.1, ABW04972.1, ABW04973.1, ABW04975.1, ABW04976.1, ABW04983.1, ABW04991.1 and ADB12239.1) [84, 85]. Hence, these R-gene sequences could be used for allele mining and mapping of resistance genes in the finger millet accessions.

\section{Calcium transport and accumulation genes}

Finger millet grain contains rich sources of nutrients, specifically it possess 5-10 times higher calcium in grains as compared to other cereals [8]. Homology based analysis identified 330 calcium transport and accumulation 
Table 3 Distribution of protein family associated with drought tolerance genes in ML-365 genome

\begin{tabular}{lll}
\hline Pfam ID & Pfam domain name & Gene count \\
\hline PF00069 & Protein kinase domain & 1386 \\
PF07714 & Protein tyrosine kinase & 546 \\
PF00651 & BTB/POZ domain & 351 \\
PF01370 & NAD dependent epimerase/dehydratase family & 175 \\
PF04564 & U-box domain & 86 \\
PF00582 & Universal stress protein family & 82 \\
PF00571 & CBS domain containing proteins (DCPS) & 77 \\
PF05699 & hAT family dimerisation domain & 36 \\
PF08879 & WRC & 32 \\
PF00999 & Sodium/hydrogen exchanger family & 20 \\
PF03061 & Thioesterase superfamily & 19 \\
PF08880 & QLQ & 16 \\
PF04185 & Phosphoesterase family & 12 \\
PF07649 & C1-like domain & 10 \\
PF00257 & Dehydrin & 10 \\
PF03107 & C1 domain & 3 \\
PF02637 & GatB domain & 3 \\
PF04147 & Nop14-like family & 2
\end{tabular}

related genes. Among 330, 28 CaM ATPase, 145 CaMK1, 125 CaMK2, 29 CAX1 and 3 TPC1 genes were identified (Additional file 9). Out of 330, six genes (g5694.t1, g73960.t1, g89161.t1, g107035.t1, g135510.t1, and g146823.t1) were found to be homologs to Calcium transport and regulation genes identified previously [31]. Large number of finger millet germplasm remain uncharacterized for several important traits, however small scale analysis of nutritional value of cultivated and wild species of Eleusine showed wider variations for protein, iron and calcium [86]. Genes identified in this study will help in exploring finger millet germplasm for calcium uptake, translocation and accumulation in various tissues in near future.

\section{C4 photosynthetic pathway genes and phylogenetic relationship}

Water scarcity has led to frequent droughts coupled with higher air temperature in many parts of the world. As a consequence, crops productivity has been negatively affected. In nature, some plants have evolved an efficient carbon concentration mechanism through $\mathrm{C} 4$ pathway to perform well under arid and hot climate. Therefore, characterization of genes associated with $\mathrm{C} 4$ pathways and their deployment could improve the efficiency of both water and nitrogen [87]. In this study, $146 \mathrm{C} 4$ pathway genes were identified that belong to seven key enzymes by functional annotation of genes of ML-365. Among 146 genes, 34 CA, 31 NAD-MDH, 21
NADP-ME, 27 PEPC, 17 PPDK, 7 PPDK-RP and 9 PPCK genes were identified in the finger millet genome (Additional file 10). Protein-protein homology based analysis with C4 genes of five cereals [12, 13] (Rice, Sorghum, Maize, Foxtail millet and Brachypodium) showed that finger millet genome has conserved C4 gene sequences by forming separate groups in majority cases. The phylogenetic tree results of phosphoenolpyruvate carboxylase (PEPC) genes showed four out of five finger millet genes formed a unique group with rice and one PEPC gene had higher homology with Brachypodium PEPC gene (Additional file 11). One of the PEPC kinase (PPCK) genes of finger millet showed homology with maize and sorghum, while remaining three genes shared ancestry with rice and sorghum (Additional file 11). Similarly, phylogenetic results of pyruvate orthophosphate dikinase (PPDK) enzyme showed that maximum number of PPDK genes were homologous to maize and sorghum (Additional file 11). Likewise, genomic comparison for PPDK-regulatory protein (PPDKRP) showed three finger millet genes shared maximum homology with foxtail millet and two genes with rice and Brachypodium. Here, sorghum and maize formed separate clade indicating their distinct origin from common ancestor (Additional file 11). Phylogenetic analysis from NADP-malate dehydrogenase (NADP-MDH), NADP-malic enzyme (NADP-ME), and carbonic anhydrase (CA) sequences revealed that finger millet genes formed a distinct group as compared to the homologous genes from other cereals under the study and shared common ancestor with sorghum, maize, foxtail millet, Brachypodium, and rice (Additional file 11). This clearly indicates that finger millet has unique copies of genes for these proteins. The presence of multiple copies of these genes indicate the possible gene duplication during the evolution of C4 pathway [88]. However, confirmation of gene numbers needs further experiments with tissuespecific transcriptome analysis. Understanding of core genes involved in C4 pathway, associated transporters $[13,89]$ and their functional characterization could help to decipher the $\mathrm{C} 4$ carbon fixation in improving drought tolerance.

\section{Conclusion}

The present study of whole genome sequencing and annotation of finger millet crop is the first report. The results on combination of paired-end and mate pair reads with variable read lengths generated from Illumina and SOLiD platforms enabled to assemble around $82 \%$ of total finger millet genome. Interestingly, almost half of the genome is interspersed with transposable elements based on de novo repeat prediction strategy. Mining of transcription factors (TFs), core C4 pathway genes, and mRNA sequencing identified large number of 
drought related TFs and drought responsive gene repertoire. These findings enable plant breeders towards advancement in deploying new breeding technologies to develop drought tolerant finger millet varieties, which could survive better in moisture stress regimes without compromising for its net productivity. Highly repetitive nature of finger millet genome and probable progenitors needs to be studied in future with the third generation sequencing technologies and sequencing of wild species, respectively. The availability of genomic resources from this study is likely to enable NGS-based allele discovery, genetic mapping, and identification of candidate genes for agronomically important traits. The genomic resources developed in this sequencing effort have been made available to the research community that will have significant impact in the near future.

\section{Additional files}

Additional file 1: Sequence data generated for ML-365 finger millet variety. (PDF $51 \mathrm{~kb}$ )

Additional file 2: NGS data analysis workflow followed for ML-365 genome and transcriptome. (PDF $118 \mathrm{~kb}$ )

Additional file 3: The CEGMA results for whole genome assembly of ML-365. (PDF $44 \mathrm{~kb}$ )

Additional file 4: Primer sequences for SSRs identified in ML-365 genome. (PDF $4301 \mathrm{~kb}$ )

Additional file 5: List of SSRs used for fingerprinting of finger millet germplasm accessions. (PDF $525 \mathrm{~kb}$ )

Additional file 6: Validation of differentially expressed drought responsive genes through qRT-PCR. (PDF $116 \mathrm{~kb}$ )

Additional file 7: Gene counts of ML-365 genome shared across other species of plants. (PDF $66 \mathrm{~kb}$ )

Additional file 8: Nucleotide sequences of resistance genes identified in ML-365 genome. (PDF $3136 \mathrm{~kb}$ )

Additional file 9: Nucleotide sequences of calcium accumulation and transportation genes identified in ML-365 genome. (PDF $485 \mathrm{~kb}$ )

Additional file 10: Protein Sequences of $C 4$ photosynthetic genes identified in ML-365 genome. (PDF $119 \mathrm{~kb}$ )

Additional file 11: Phylogenetic tree of C4 pathway depicting the sharing of common ancestry among different cereals. (PDF $1716 \mathrm{~kb}$ )

\section{Abbreviations}

ATP: Adenosine triphosphate; BAC: Bacterial artificial chromosome; CC: Coiled-coil; CDPK: Calmodulin dependent protein kinase; CEG: Core eukaryotic genes; Gb: Giga bases; Gl: Glycemic index; GO: Gene ontology; Kb: Kilo bases; LMS: Low moisture stress; LRR: Leucine rich repeats; LTR: Long terminal repeats; Mb: Mega bases; pg: Pico gram; PKs: Protein kinases; PUTs: Putative transcripts; SSRs: Simple sequence repeats; TFs: Transcription factors; WW: Well-watered

\section{Acknowledgements}

We acknowledge Project co-ordinator, All India Coordinated Research Project on Small Millets, University of Agricultural Sciences (UAS), Bengaluru for providing seeds of finger millet core collection.

\section{Funding}

This project was a competitive grant from World Bank under the Sujala-II funded by Watershed Development Department, Government of Karnataka, India to Shailaja Hittalmani as a Principal Investigator. The funding agency had no role in study design, data collection, analysis and interpretation, decision to publish, or preparation of the manuscript.

\section{Availability of data and materials}

The whole genome assembly has been deposited at NCBI/DDBJ/EMBL with the accession ID LXGH00000000. The version described in this paper is LXGH01000000. The raw sequence reads of whole genome and RNA sequencing is deposited in NCBI SRA database with the accession number SRP081350. Finger millet germplasm lines used in this study are maintained in our institute at All India Coordinated Research Project on Small Millets, University of Agricultural Sciences (UAS), Bengaluru, India and available on request as per germplasm exchange guidelines.

\section{Author's contributions}

HBM designed the experiment, genome estimation, performed genome assembly and functional annotation, gene family analysis, transcription factors mining, repeat identification, gene expression analysis, analysed C4, resistance and Calcium transport pathway genes, performed qRT-PCR submitted genome and raw sequence data to NCBl, prepared all tables, figures and wrote the manuscript. SH planned and conceived the project, wrote the project proposal, fund acquisition, interacted with sequencing providers and edited the manuscript. MDS performed the orthoMCL analysis and helped in writing the manuscript. $\mathrm{HB}$ analysed C4 pathway genes, DNA finger printing and wrote the part of manuscript. AYR and UG isolated the DNA and fingerprinted the germplasm accessions. HCL helped in project execution and edited the manuscript. AMR edited the manuscript. All authors read and approved the final manuscript.

\section{Competing interests}

The authors declare that they have no competing of interests.

\section{Consent for publication}

Not applicable.

Ethics approval and consent to participate

Not applicable.

\section{Publisher's Note}

Springer Nature remains neutral with regard to jurisdictional claims in published maps and institutional affiliations.

\section{Author details}

${ }^{1}$ Marker Assisted Selection Laboratory, Department of Genetics and Plant Breeding, University of Agricultural Sciences, Bengaluru 560065, India. ${ }^{2}$ Manipal University, Manipal 576104, India. ${ }^{3}$ Department of Genetics and Plant Breeding, College of Agriculture, V. C. Farm, University of Agricultural Sciences, Mandya 571405, India.

Received: 23 January 2017 Accepted: 7 June 2017

Published online: 15 June 2017

\section{References}

1. Hilu K. Validation of the combination Eleusine coracana subspecies africana (Kennedy-O'Byrne) Hilu et Dewet. Phytologia. 1994;76(5):410-1.

2. Hilu KW, De Wet J. Domestication of Eleusine coracana. Econ Bot. 1976:30(3): 199-208.

3. Chennaveeraiah M, Hiremath S. Genome analysis of Eleusine coracana (L.) Gaertn. Euphytica. 1974;23(3):489-95.

4. Dida MM, Wanyera N, Dunn MLH, Bennetzen UL, Devos KM. Population structure and diversity in finger millet (Eleusine coracana) germplasm. Trop Plant Biol. 2008;1(2):131-41.

5. Hilu K, Johnson J. Ribosomal DNA variation in finger millet and wild species of Eleusine (Poaceae). Theor Appl Genet. 1992;83(6-7):895-902.

6. Upadhyaya H, Gowda C, Reddy VG. Morphological diversity in finger millet germplasm introduced from Southern and Eastern Africa. J SAT Agric Res. 2007;3(1):1-3.

7. Vetriventhan M, Upadhyaya HD, Dwivedi SL, Pattanashetti SK, Singh SK. Finger and foxtail millets. In: Genetic and Genomic Resources for Grain Cereals Improvement. USA: Academic Press, Elsevier; 2015. p. 291-319.

8. Kumar A, Metwal M, Kaur S, Gupta AK, Puranik S, Singh S, Singh M, Gupta S, Babu BK, Sood S. Nutraceutical Value of Finger Millet [Eleusine coracana (L.) 
Gaertn.], and Their Improvement Using Omics Approaches. Front Plant Sci. 2016;7. doi:10.3389/fpls.2016.00934.

9. Chandrashekar A. Finger millet: Eleusine coracana. Adv Food Nutr Res. 2010; 59:215-62.

10. Duke JA, Wain K. Medicinal plants of the world. In: Computer index with more than 85000 entries. Beltsville, Maryland: Plant Genetics and Germplasm Institute, Agricultural Research Service; 1981: 12-16.

11. Pradhan A, Nag S, Patil S. Dietary management of finger millet (Eleusine coracana L. Gaerth) controls diabetes. Curr Sci. 2010;98(6):763-5.

12. Wang X, Gowik U, Tang H, Bowers JE, Westhoff P, Paterson AH. Comparative genomic analysis of $\mathrm{C} 4$ photosynthetic pathway evolution in grasses. Genome Biol. 2009;10(6):1.

13. Huang P, Studer AJ, Schnable JC, Kellogg EA, Brutnell TP: Cross species selection scans identify components of C4 photosynthesis in the grasses. J Exp Bot. 2016;68(2):127-135. https://doi.org/10.1093/jxb/erw256.

14. Saha D, Gowda MC, Arya L, Verma M, Bansal KC. Genetic and genomic resources of small millets. Crit Rev Plant Sci. 2016;35(1):56-79.

15. Gandhi RV, Hittalmani S, Babu NN. Performance of new ragi variety ML 365 by adopting production technology in southern Karnataka, India. Int J Plant Sci. 2012;7(1):176-80.

16. Krishan A. Rapid flow cytofluorometric analysis of mammalian cell cycle by propidium iodide staining. J Cell Biol. 1975;66(1):188-93.

17. Baranyi $\mathrm{M}$, Greilhuber J. Flow cytometric analysis of genome size variation in cultivated and Wildpisum sativum (Fabaceae). Plant Syst Evol. 1995;194(3):231-9.

18. Baranyi M, Greilhuber J, Swięcicki W. Genome size in wild Pisum species. TAG Theor Appl Genet. 1996;93(5):717-21.

19. Doležel J, Bartoš J. Plant DNA flow cytometry and estimation of nuclear genome size. Ann Bot. 2005;95(1):99-110.

20. Bennett MD, Smith J: Nuclear DNA amounts in angiosperms. Philos Trans $R$ Soc Lond Ser B Biol Sci 1976, 274(933):227-274.

21. Ramegowda V, Senthil-Kumar M, Nataraja KN, Reddy MK, Mysore KS, Udayakumar M. Expression of a finger millet transcription factor, EcNAC1, in tobacco confers abiotic stress-tolerance. PLoS One. 2012;7(7):e40397.

22. Luo R, Liu B, Xie Y, Li Z, Huang W, Yuan J, et al. SOAPdenovo2: an empirically improved memory-efficient short-read de novo assembler. Gigascience. 2012:1 (1):18

23. Boetzer M, Henkel CV, Jansen HJ, Butler D, Pirovano W. Scaffolding preassembled contigs using SSPACE. Bioinformatics. 2011;27(4):578-9.

24. Parra G, Bradnam K, Korf I. CEGMA: a pipeline to accurately annotate core genes in eukaryotic genomes. Bioinformatics. 2007;23(9):1061-7.

25. Stanke M, Keller O, Gunduz I, Hayes A, Waack S, Morgenstern B. AUGUSTUS: ab initio prediction of alternative transcripts. Nucleic Acids Res. 2006; 34(suppl 2):W435-9.

26. Moriya Y, Itoh M, Okuda S, Yoshizawa AC, Kanehisa M. KAAS: an automatic genome annotation and pathway reconstruction server. Nucleic Acids Res. 2007;35(suppl 2):W182-5.

27. Jones $P$, Binns $D$, Chang H-Y, Fraser M, Li W, McAnulla C, et al. InterProScan 5 : genome-scale protein function classification. Bioinformatics. 2014;30(9):1236-40.

28. Li L, Stoeckert CJ, Roos DS. OrthoMCL: identification of ortholog groups for eukaryotic genomes. Genome Res. 2003;13(9):2178-89.

29. Hittalmani S, Mahesh H, Mahadevaiah C, Prasannakumar MK. De novo genome assembly and annotation of rice sheath rot fungus Sarocladium oryzae reveals genes involved in Helvolic acid and Cerulenin biosynthesis pathways. BMC Genomics. 2016;17(1):1.

30. Soderlund C, Nelson W, Shoemaker A, Paterson A. SyMAP: A system for discovering and viewing syntenic regions of FPC maps. Genome Res. 2006; 16(9):1159-68

31. Mirza N, Taj G, Arora S, Kumar A. Transcriptional expression analysis of genes involved in regulation of calcium translocation and storage in finger millet (Eleusine coracana L. Gartn.). Gene. 2014;550(2):171-9.

32. Singh UM, Metwal M, Singh M, Taj G, Kumar A. Identification and characterization of calcium transporter gene family in finger millet in relation to grain calcium content. Gene. 2015;566(1):37-46.

33. Li W, Cowley A, Uludag M, Gur T, McWilliam H, Squizzato S, et al. The EMBLEBI bioinformatics web and programmatic tools framework. Nucleic Acids Res. 2015:43(W1):W580-4.

34. Grabherr MG, Haas BJ, Yassour M, Levin JZ, Thompson DA, Amit I, et al. Trinity: reconstructing a full-length transcriptome without a genome from RNA-Seq data. Nat Biotechnol. 2011;29(7):644-52.

35. Li W, Godzik A. Cd-hit: a fast program for clustering and comparing large sets of protein or nucleotide sequences. Bioinformatics. 2006;22(13):1658-9.
36. Annadurai RS, Neethiraj R, Jayakumar V, Damodaran AC, Rao SN, Katta MA et al. De Novo transcriptome assembly (NGS) of Curcuma longa L. rhizome reveals novel transcripts related to anticancer and antimalarial terpenoids. PLoS One. 2013:8(2):e56217.

37. Gahlan P, Singh HR, Shankar R, Sharma N, Kumari A, Chawla V, et al. De novo sequencing and characterization of Picrorhiza kurrooa transcriptome at two temperatures showed major transcriptome adjustments. BMC Genomics. 2012;13(1):126.

38. Langmead B, Salzberg SL. Fast gapped-read alignment with Bowtie 2. Nat Methods. 2012;9(4):357-9.

39. Anders S, Huber W. Differential expression analysis for sequence count data. Genome Biol. 2010;11(10):1.

40. Thiel T, Michalek W, Varshney R, Graner A. Exploiting EST databases for the development and characterization of gene-derived SSR-markers in barley (Hordeum vulgare L.). Theor Appl Genet. 2003;106(3):411-22.

41. Temnykh S, DeClerck G, Lukashova A, Lipovich L, Cartinhour S, McCouch S Computational and experimental analysis of microsatellites in rice (Oryza sativa L.): frequency, length variation, transposon associations, and genetic marker potential. Genome Res. 2001:11(8):1441-52.

42. Schuler GD. Sequence mapping by electronic PCR. Genome Res. 1997;7(5): $541-50$.

43. Dellaporta S, Wood J, Hicks J. A plant DNA minipreparation: Version II. Plant Mol Biol Rep. 1983;1(4):19-21.

44. Neves SS, Swire-Clark G, Hilu KW, Baird WV. Phylogeny of Eleusine (Poaceae: Chloridoideae) based on nuclear ITS and plastid trnT-trnF sequences. Mol Phylogen Evol. 2005;35(2):395-419.

45. Hilu KW. Identification of the "A" genome of finger millet using chloroplast DNA. Genetics. 1988;118(1):163-7.

46. Bisht M, Mukai Y. Genomic in situ hybridization identifies genome donor of finger millet (Eleusine coracana). Theor Appl Genet. 2001;102(6-7):825-32.

47. Bisht MS, Mukai Y. Mapping of rDNA on the chromosomes of Eleusine species by fluorescence in situ hybridization. Genes Genet Syst. 2000;75(6): 343-8.

48. Bisht MS, Mukai Y. Identification of Genome Donors to the Wild Species of Finger Millet, Eleusine africana by Genomic in situ Hybridization. Breed Sci. 2001:51(4):263-9.

49. Liu Q, Jiang B, Wen J, Peterson PM. Low-copy nuclear gene and McGISH resolves polyploid history of Eleusine coracana and morphological character evolution in Eleusine. Turk J Bot. 2014;38(1):1-12.

50. Sood S, Babu BK. Finger Millet. In: Broadening the Genetic Base of Grain Cereals. India: Springer. 2016:225-256.

51. Oduori C, Kanyenji B. Finger millet in Kenya: Importance, advances in R\&D, challenges and opportunities for improved production and profitability. Finger Millet Blast Management in East Africa Creating opportunities for improving production and utilization of finger millet. Nairobi: Proceedings of the First International Finger Millet Stakeholder Workshop. 2005:10-22.

52. Upadhyaya HD, Gowda CL, Pundir RP, Reddy VG, Singh S. Development of core subset of finger millet germplasm using geographical origin and data on 14 quantitative traits. Genet Resour Crop Evol. 2006;53(4):679-85.

53. Dida MM, Ramakrishnan S, Bennetzen JL, Gale MD, Devos KM. The genetic map of finger millet, Eleusine coracana. Theor Appl Genet. 2007;114(2):321-32.

54. Yadav S, Gaur VS, Jaiswal J, Kumar A. Simple sequence repeat (SSR) analysis in relation to calcium transport and signaling genes reveals transferability among grasses and a conserved behavior within finger millet genotypes. Plant Syst Evol. 2014:300(6):1561-8.

55. Kumar A, Yadav S, Panwar P, Gaur V, Sood S. Identification of Anchored Simple Sequence Repeat Markers Associated with Calcium Content in Finger Millet (Eleusine coracana). Proc Natl Acad Sci India B Biol Sci. 2015;85(1):311-7.

56. Fakrudin B, Shashidhar H, Kulkarni R, Hittalmani S. Genetic diversity assessment of finger millet, Eleusine coracana (Gaertn), germplasm through RAPD analysis. PGR Newslett. 2004;138:50-4.

57. Purugganan MD, Rounsley SD, Schmidt RJ, Yanofsky MF. Molecular evolution of flower development: diversification of the plant MADS-box regulatory gene family. Genetics. 1995;140(1):345-56.

58. Bennetzen JL. Mechanisms and rates of genome expansion and contraction in flowering plants. Genetica. 2002;115(1):29-36.

59. Srinivasachary, Dida MM, Gale MD, Devos KM. Comparative analyses revea high levels of conserved colinearity between the finger millet and rice genomes. Theor Appl Genet. 2007;115(4):489-99.

60. Babu BK, Agrawal P, Pandey D, Kumar A. Comparative genomics and association mapping approaches for opaque2 modifier genes in finger 
millet accessions using genic, genomic and candidate gene-based simple sequence repeat markers. Mol Breed. 2014;34(3):1261-79.

61. Babu BK, Pandey D, Agrawal P, Sood S, Kumar A. In-silico mining, type and frequency analysis of genic microsatellites of finger millet (Eleusine coracana (L.) Gaertn.): a comparative genomic analysis of NBS-LRR regions of finger millet with rice. Mol Biol Rep. 2014;41(5):3081-90.

62. Nath M, Goel A, Taj G, Kumar A. Molecular cloning and comparative in silico analysis of calmodulin genes from cereals and millets for understanding the mechanism of differential calcium accumulation. J Proteomics Bioinform. 2010:3:294-301.

63. Wang L, Czedik-Eysenberg A, Mertz RA, Si Y, Tohge T, Nunes-Nesi A, et al. Comparative analyses of $C 4$ and $C 3$ photosynthesis in developing leaves of maize and rice. Nat Biotechnol. 2014;32(11):1158-65.

64. Gupta VS, Ranjekar P. DNA sequence organization in finger millet (Eleusine coracana). J Biosci (Bangalore). 1981;3(4):417-30.

65. Wimpee CF, Rawson JR. Characterization of the nuclear genome of pearl millet. Biochim Biophys Acta. 1979;562(2):192-206.

66. Gimode D, Odeny DA, de Villiers EP, Wanyonyi S, Dida MM, Mneney EE, et al. Identification of SNP and SSR Markers in Finger Millet Using Next Generation Sequencing Technologies. PLoS One. 2016;11(7):e0159437.

67. Salimath SS, Oliveira AC, Bennetzen JL, Godwin ID. Assessment of genome origins and genetic diversity in the genus Eleusine with DNA markers. Genome. 1995;38(4):757-63.

68. Kumar A, Sharma D, Tiwari A, Jaiswal J, Singh N, Sood S. Genotyping-bySequencing analysis for determining population structure of finger millet germplasm of diverse origins. Plant Genome. 2016;9:2.

69. Singh RK, Singh VK, Raghavendrarao S, Phanindra MLV, Raman KV, Solanke AU, et al. Expression of finger millet EcDehydrin7 in transgenic tobacco confers tolerance to drought stress. Appl Biochem Biotechnol. 2015;177(1):207-16.

70. Babitha K, Vemanna RS, Nataraja KN, Udayakumar M. Overexpression of EcbHLH57 Transcription Factor from Eleusine coracana L. in Tobacco Confers Tolerance to Salt, Oxidative and Drought Stress. PLoS One. 2015;10(9): e0137098.

71. Rahman H, Ramanathan V, Nallathambi J, Duraialagaraja S, Muthurajan R. Over-expression of a NAC 67 transcription factor from finger millet (Eleusine coracana L.) confers tolerance against salinity and drought stress in rice. BMC Biotechnol. 2016;16(1):7.

72. Singh KB, Foley RC, Oñate-Sánchez L. Transcription factors in plant defense and stress responses. Curr Opin Plant Biol. 2002;5(5):430-6.

73. Liu Q, Kasuga M, Sakuma Y, Abe H, Miura S, Yamaguchi-Shinozaki K, et al. Two transcription factors, DREB1 and DREB2, with an EREBP/AP2 DNA binding domain separate two cellular signal transduction pathways in drought-and low-temperature-responsive gene expression, respectively, in Arabidopsis. Plant Cell. 1998;10(8):1391-406.

74. Vinocur B, Altman A. Recent advances in engineering plant tolerance to abiotic stress: achievements and limitations. Curr Opin Biotechnol. 2005; 16(2):123-32.

75. Yamaguchi-Shinozaki K, Shinozaki K. Transcriptional regulatory networks in cellular responses and tolerance to dehydration and cold stresses. Annu Rev Plant Biol. 2006;57:781-803.

76. Gaj T, Gersbach CA, Barbas CF. ZFN, TALEN, and CRISPR/Cas-based methods for genome engineering. Trends Biotechnol. 2013;31(7):397-405.

77. Rabara RC, Tripathi P, Rushton PJ. The potential of transcription factor-based genetic engineering in improving crop tolerance to drought. OMICS. 2014; 18(10):601-14

78. Shirke MD, Mahesh H, Gowda M. Genome-Wide Comparison of Magnaporthe Species Reveals a Host-Specific Pattern of Secretory Proteins and Transposable Elements. PLoS One. 2016;11(9):e0162458.

79. Nagaraja A, Jagadish P, Ashok E, Gowda KK. Avoidance of finger millet blast by ideal sowing time and assessment of varietal performance under rain fed production situations in Karnataka. J Mycopathol Res. 2007;45(2):237-40.

80. Rao A. Estimates of losses in finger millet (Eleusine coracana) due to blast disease (Pyricularia grisea). Mysore J Agric Sci. 1990;24(1):57-60.

81. Mahesh H, Shirke MD, Singh S, Rajamani A, Hittalmani S, Wang G-L, et al Indica rice genome assembly, annotation and mining of blast disease resistance genes. BMC Genomics. 2016;17(1):1.

82. Babu BK, Dinesh P, Agrawal PK, Sood S, Chandrashekara C, Bhatt JC, et al. Comparative genomics and association mapping approaches for blast resistant genes in finger millet using SSRs. PLoS One. 2014;9(6):e99182.

83. Ramakrishnan M, Ceasar SA, Duraipandiyan V, Vinod K, Kalpana K, Al-Dhabi $\mathrm{N}$, et al. Tracing QTLs for Leaf Blast Resistance and Agronomic Performance of Finger Millet (Eleusine coracana (L.) Gaertn.) Genotypes through Association Mapping and in silico Comparative Genomics Analyses. PLoS One. 2016;11(7):e0159264.

84. Saha D, Rana RS. Cloning and analysis of the NBS-LRR gene family in finger millet (Eleusine coracana L.)(Gaertn.). Plant Knowledge J. 2016;5(1):1-8.

85. Reddy IBL, Reddy DS, Narasu ML, Sivaramakrishnan S. Characterization of disease resistance gene homologues isolated from finger millet (Eleusine coracana L. Gaertn). Mol Breed. 2011;27(3):315-28.

86. Vadivoo AS, Joseph R, Ganesan NM. Genetic variability and diversity for protein and calcium contents in finger millet (Eleusine coracana (L.) Gaertn) in relation to grain color. Plant Foods Hum Nutr. 1998:52(4):353-64.

87. Ding Z, Weissmann S, Wang M, Du B, Huang L, Wang L, et al. Identification of Photosynthesis-Associated C 4 Candidate Genes through Comparative Leaf Gradient Transcriptome in Multiple Lineages of C 3 and C 4 Species. PLoS One. 2015;10(10):e0140629.

88. Monson RK. Gene duplication, neofunctionalization, and the evolution of C4 photosynthesis. Int J Plant Sci. 2003;164(S3):S43-54.

89. John CR, Smith-Unna RD, Woodfield H, Covshoff S, Hibberd JM. Evolutionary convergence of cell-specific gene expression in independent lineages of C4 grasses. Plant Physiol. 2014;165(1):62-75.

\section{Submit your next manuscript to BioMed Central and we will help you at every step:}

- We accept pre-submission inquiries

- Our selector tool helps you to find the most relevant journal

- We provide round the clock customer support

- Convenient online submission

- Thorough peer review

- Inclusion in PubMed and all major indexing services

- Maximum visibility for your research

Submit your manuscript at www.biomedcentral.com/submit
) Biomed Central 